\title{
Ressonâncias do envolvimento e participação com os meios
}

I/I/I/I/I/I/I/I/II I Irene Machado ${ }^{1}$

1. Professora livre-docente no Programa de Pós-Graduação em Comunicação e no Departamento de Comunicações e Artes da Escola de Comunicações e Artes da Universidade de São Paulo. E-mail: irenemac@uol.com.br 


\section{Resumo}

Problematizando a noção de meios quentes e frios como classificação, propõe-se discutir os processos de envolvimento e participação "com os e nos" meios como exercício de percepção e cognição. Para isso, segue-se na continuidade das explorações de M. McLuhan sobre o caminho explicativo do pensamento icônico. Da análise dos padrões de codificação em telas de luz, observam-se os processos de transdução da informação e a constituição dos espaços de simultaneidade temporal. Esses são os espaços de resistência e de revisão conceitual discutidos no ensaio.

\section{Palavras-chave}

percepção, cognição, espaço ressonante, códigos elétricos, transdução

\section{Abstract}

Inquiring the notion of hot and cold media such as classification, it is proposed here to discuss the processes of involvement and participation, with and in the media, as an exercise in perception and cognition. For this, the article follows on from M. McLuhan explorations on the line of explanation of iconic thought. From the analysis of the coding patterns for light screens it was deduced processes of information transduction and the generation of spaces of simultaneity in time. These are the spaces of resistance and conceptual revision discussed in the essay.

\section{Key-words}

perception, cognition, resonance space, electric codes, transduction 


\section{Espaço crítico de resistência}

No calor das muitas comemorações do centenário de nascimento Herbert Marshall McLuhan (1911-1980), não houve nada de surpreendente na revisão de suas formulações polêmicas. Se serviram para reposicionar, ou minimizar desafetos, se encarregaram também de promover reconhecimentos que a história, em nenhum momento, legou ao esquecimento. Não devido à desenvoltura dos meios tecnológicos, ou à configuração atual da comunicação em rede, mas sim porque McLuhan desenvolveu um trabalho de entendimento com base nas transformações tecnológicas, bem como na percepção e na cognição adquiridas a partir delas. Nenhuma dessas ações prescinde do amadurecimento histórico e de educação.

Por conseguinte, o entendimento dos meios cresceu e se consolidou como área de investigação no campo científico. E isso é um fato. Não se trata de remissão de ressentimentos nem de confirmação de profecias. Se as ideias foram satisfatoriamente compreendidas, ainda não é possível afirmar - sobretudo quando a acusação de determinismo tecnológico continua a paralisar os julgamentos.

Apesar de bem-sucedidas, as comemorações deixaram à mostra algumas tensões no espaço crítico (VIRILIO, 1993) de um pensamento não afeito a demonstrações empíricas de última hora. Por um lado, é notória a constatação de que algumas noções, antes condenadas, tenham sido resgatadas e justificadas no contexto das redes. As noções de meios como extensão (McLUHAN, 
1998; 1971) e de "aldeia global" (McLUHAN \& POWERS, 1996) assumem a posição de fatos comprovados, e não de chaves conceituais para investigação (LOGAN, 2010; PEREIRA, 2011). Por outro lado, noções que compuseram o campo das explorações de McLuhan, com implicações não diretamente implícitas, tais como os princípios de meios quentes e frios (McLUHAN, 1971; 1998), foram consideradas o grande equívoco do profeta, merecendo ser banidas, sem direito a nenhum voto de credibilidade, sob o risco de ofuscar os festejos e as comemorações dos bem-sucedidos empreendimentos conceituais do guru midiático. O descarte ora proposto merece, contudo, ponderações.

Qualquer campo exploratório e especulativo se define, antes de mais nada, pelas hipóteses que elabora, não pelos resultados ou pelas teses que comprovam. Conta-se, por conseguinte, com a possibilidade de não verificação de muitas das hipóteses. Trata-se, pois, de um campo de probabilidade, de incerteza. Nada impede, porém, a sobrevida do raciocínio e do método em prol de outras formulações mais vigorosas, ou de eliminação da incerteza. Esse parece ser o caso das ideias de McLuhan sobre os meios quentes e frios. Concebidas como hipóteses para pensar o grau de envolvimento e participação com os meios, não se consagraram como classificação, visto que, no processo investigativo, serviram apenas de princípio heurístico, subsidiando encaminhamentos ulteriores. Contudo, foram fundamentais para a observação de ocorrências perceptuais e cognitivas - o mais caro empreendimento do legado teórico de McLuhan voltado para o estudo dos meios e dos processos interativos da comunicação. Ao atribuir aos meios um gradiente performático, sobretudo no que diz respeito ao envolvimento e à participação, McLuhan deslocou sua atenção para os diferentes modelos processuais desenvolvidos culturalmente pelos meios de comunicação.

Se o raciocínio estiver certo, é possível reconhecer que eliminar o princípio de partida significa dissimular o espaço crítico a partir do qual se processou o entendimento dos meios de comunicação e de seus efeitos perceptuais e cognitivos. Espaço crítico que bancou uma revisão da consagrada noção de espaço visual como continente para coisas em nome da simultaneidade do tempo-espaço ressonante (CARPENTER \& MCLUHAN, 1980; CAVELL, 2002; McLUHAN \& PARKER, 1975; McLUHAN \& POWERS, 1996). 
Vale lembrar que a mera classificação dos meios em quentes ou frios não leva a lugar nenhum se dela for descartado o efeito de envolvimento e participação. Com base nesse efeito conjugado é que se delineou a complexa reflexão sobre espaço e ambiente de comunicação, em que se desenvolvem processos integrados, responsáveis pela emergência das combinatórias geradoras dos meios audiovisuais e cinéticos e dos arranjos que se convencionou chamar mídias de tela. Logo, em vez de descartar a classificação, recomenda-se examinar o campo de sua intervenção.

Isso posto, comecemos por esclarecer os conceitos em foco.

\section{Princípios heurísticos da análise}

"Quente" e "frio" são termos empregados na vida cotidiana da linguagem para afirmar o grau de aproximações e distanciamentos de sentido, ou melhor, efeitos de sentido. Reportam-se ao conhecimento tácito que, na gíria, inverteu o significado da palavra, como observou McLuhan ao adotá-los como predicados sobre os graus de envolvimento criado pelos meios: "A idéia de que frio mudou de significado tem certa base no fato de nossa cultura ter passado a colocar grande parte de sua ênfase numa exigência de estarmos mais comprometidos, mais envolvidos em situações nas quais costumávamos trabalhar" (McLUHAN, 2005, p. 104).

Transpostos para o contexto da cultura e dos meios, os predicados "quente" e "frio" passam a designar o nível de informação inversamente proporcional ao grau de participação. Quanto maior o nível de informação, maior o acabamento e, portanto, menores o envolvimento e a participação. Nos exercícios em que realiza seu treino de percepção, McLuhan mostra como a fotografia se constitui num meio quente se relacionada ao cartum ou à charge; como a televisão corresponde a um meio frio se comparada com o cinema; ou, ainda, como o jazz convida muito mais à participação do que a música clássica. Com relação a esta última, observou também as diferenças entre o envolvimento da música na sala de concertos e da música gravada, servindo-se, para isso, da análise do trabalho do consagrado pianista canadense Glenn Gould. Com esses exercícios, montou um raciocínio, alguns princípios heurísticos necessários para a construção de hipóteses explicativas. Assim, são pontos 
de partida com vistas ao entendimento, não uma mera tabela de classificação. Diríamos que se trata da formulação de um método especulativo baseado em comparações.

Delineia-se um importante alvo, que McLuhan e seus colaboradores constituíram como um legado para o entendimento dos meios e de seus processos de interação na cultura. Enquanto a palavra oral convida à participação potencial do sensório como um todo, a palavra escrita, desde seu aparecimento (McLUHAN \& McLUHAN, 1988), se concentrou prioritariamente na visualidade de suas formas gráficas, ainda que poetas, artistas e designers procurem desafiá-las. Em contraposição, a cultura visual viu proliferar em seu interior formas diversificadas quando ela própria passa a integrar o contexto da eletricidade. O que se observa é uma explosão de formas de envolvimento e participação que forjam relações de complementaridade entre os meios de modo a operar tanto de um modo quanto de outro. Em vez de estabilizar, relativiza os modelos de percepção e de cognição. Um exemplo a que McLuhan recorre é o humor (McLUHAN, 2005; McLUHAN \& FIORE, 1967). Segundo ele, uma piada elabora diferentes níveis de participação, uma vez que mobiliza diferentes esferas de interação cultural, não limitada ao domínio linguístico. Se aquele que ouve não estiver integrado ao contexto relacional ali convocado, de nada adiantará afirmar que a palavra é um meio de grande participação e envolvimento. Ocorre, pois, um deslocamento: não se trata de definir de uma vez por todas a natureza do meio, mas de compreender as diferentes formas de interação que ele é capaz de movimentar no contexto de sua inserção. É de percepção e de cognição que estamos falando.

Ao mudar o foco, perguntamos: como um princípio binário meramente indicativo pôde encaminhar um empreendimento conceitual de tamanha envergadura? Lembremos, a propósito, que é de envolvimento, com diferentes graus de participação, que tratam as concepções de meios como ambiente, de espaço acústico como integração, de ecologia como interação sistêmica.

Deixemos anotada a questão que nos impede de desqualificar as noções de meios quentes e frios como princípios de análise. Mais do que uma fórmula classificatória, o binômio equaciona, para além dos termos, as relações associativas próprias de todo gesto que colabora na constituição de uma forma de pensamento e de interação. Nesse sentido, participação e envolvimento não podem ser 
limitados à mecânica de suas performances elementares, mas devem ser dimensionados em seus desdobramentos. Enfatiza-se, pois, uma dinâmica que problematiza o próprio conceito de espaço e, por conseguinte, de ambiente. Nele, percepções e atos cognitivos se encarregam de projetar as relações qualitativas que alcançam o pensamento em sua configuração icônica. Noções como espaço acústico e pensamento icônico se reportam diretamente à dinâmica de envolvimento e participação "dos e com os" meios na escalada rumo ao entendimento do ponto de vista de seus efeitos. Para a abordagem semiótica da cultura, trata-se de um contexto de geração de semiose e dos espaços interpretantes, sem os quais os sistemas da cultura não se desenvolvem sistemicamente.

Diante desse quadro de implicações tão intimamente equacionadas, julgamos ser impossível descartar os princípios formulados por McLuhan, ainda que pesem os equívocos de interpretação. Propomos, então, refletir sobre tais formulações do ponto de vista dos espaços críticos de resistência que as concepções alcançaram em seu desdobramento. Em vez de um movimento demonstrativo e redentor, interessa-nos acompanhar o tensionamento processual de implicações de largo espectro. Logo, aquilo que supostamente seria descartado graças à precariedade de consistência teórica, pode ser considerado como uma hipótese explicativa de um princípio heurístico em desenvolvimento.

Em estudos anteriores, tratamos da percepção do espaço acústico e de suas ressonâncias ambientais. É chegada a hora de acompanhar as linhas de raciocínio sobre as mudanças cognitivas, isto é, a mente em contato com os meios - aquilo que McLuhan propõe em termos de mecanismos genericamente designados de "pensamento icônico". No exame dos graus de envolvimento e participação com os meios e os processos de comunicação, observam-se não apenas o funcionamento perceptual, mas, sobretudo, a livre associação e os cruzamentos sensoriais naquilo que emerge como elementar no pensamento: o raciocínio associativo, ou juízos perceptivos, a intuição e a abdução. Quando vislumbra o "homem icônico" no contexto dos meios eletrônicos, McLuhan não anuncia uma vaticínio, mas sim uma hipótese explicativa daquilo que, no campo dos estudos semióticos, se define como ação dos signos em semiose cultural. O que se propõe na sequência é nosso entendimento da semiose dos sistemas culturais eletrônicos. 


\section{Diagramas do pensamento icônico}

A ideia de que os meios de comunicação criam formas de envolvimento e de participação não apenas representa a dinâmica das relações socioculturais como também mostra o trabalho da percepção no desenvolvimento cognitivo. No campo dos estudos semióticos, diz respeito ao trabalho do próprio pensamento, em que percepção e cognição abrangem aquelas operações pelas quais se torna possível considerar processos de representação e de conhecimento baseados na experiência do mundo sensorial. A noção de que o pensamento não apenas corresponde a manifestações sígnicas como também compõe diagramas relacionais, com os quais dimensiona as diferentes formas de raciocínios despertados na experiência, sintetiza o eixo conceitual do pragmatismo de Peirce (1980, p. 5-60). Nos estudos da "signicidade" do pensamento, diferentes linhas de compreensão da semiose foram desenvolvidas. É nela que encontramos a orientação elementar sobre o processo icônico do pensamento em sua atividade associativa e relacional, que reserva um papel significativo para a relação de similaridade e, consequentemente, para a metáfora e os seus desdobramentos. Vale dizer que, por meio da similaridade, o pensamento apresenta uma representação possível daquilo que investiga segundo as hipóteses explicativas emergentes.

$\mathrm{Na}$ teoria geral dos signos, denomina-se ícone a classe de signos que opera por similaridade, criando assim uma aproximação possível dos objetos aos quais se refere. Tomadas como formulações de generalidade, tais relações de similaridade articulam linhas gerais, imagens ou padrões de constituição, senão do objeto, pelo menos do modo como ele se manifesta no entendimento. Nesse sentido, o ícone se revela como elaboração de pensamento em seu modo operativo de raciocinar por meio de generalidades. Cumpre-se, pois, um caminho de relações mentais articuladas que sugerem a composição de um "constructo" mental que Peirce (1933, p. 4.418) denomina "diagrama" . Por sua condição de similaridade, o diagrama foi compreendido como signo icônico, aquele que representa traços de generalidades dos objetos num dado presente e numa dada atualidade.

Porque sua característica elementar é a relação de similaridade, o diagrama reconstitui caminhos que levam à formação do signo icônico no modus operandi do próprio pensamento. Assim, o diagrama estabelece relações diretas com o contexto vivo da experiên-
2. Ver também: DELEUZE, 1993. 
cia. Em última análise, gera um lugar de experimentação que, sob forma de raciocínios, compõe signos icônicos em representações.

Quando tratamos do signo icônico, buscamos compreender articulações de similaridade que tracem caminhos de raciocínio. Denominamos "diagramas" as relações em seus passos explicativos. Em termos muito gerais, chegamos à compreensão de uma relação dinâmica que implica percepção e cognição na experiência.

Diferentes campos da teoria semiótica se constituíram para examinar as diferentes manifestações disso que designamos genericamente por experiência. Podemos pensar tanto na vida como experiência dos organismos, na continuidade da vida que gera vida (sinequismo para Peirce; biosfera para V. Vernadsky; semiosfera para I. Lotman), quanto naquela experiência transformadora e geradora de formas de representação que se consagrou como a vida da cultura, em que a cultura humana emerge como elaboração de pensamento igualmente humano. Aqui a experiência figura como um processo produtivo de informação, que já foi entendido como um cosmos primordial de movimento organizado. Nesse sentido, alcançamos um outro entendimento de experiência: a organização da informação contínua, que o pensamento cibernético definiu como comunicação (WIENER, 1968) e a semiótica da cultura entendeu como mecanismo de transformação da informação em linguagem ou texto de cultura (LOTMAN, 1996). Quando falamos de organização, já estamos mergulhados no processo orientado pela atividade transformadora da percepção e da cognição, que desenhamos aqui graças ao pensamento icônico desenvolvido pela teoria semiótica.

Considera-se, assim, que o diagrama de nosso pensamento cumpre o caminho de organização da informação e, para isso, conta com a mente perceptora e cognitiva, capaz de operar semioses e transformar-se em linguagem, oferecendo representações sígnicas. Em semiose, reporta-se a mediações de linguagem e de códigos criados culturalmente para representar as transformações de percepções. O grande desafio que enfrentamos é o fato de não haver questionamento quanto à natureza da fala humana como linguagem. Contudo, há muita interrogação quanto ao entendimento de meio de comunicação como linguagem. Nenhuma dúvida quanto às formas gráficas do alfabeto, mas todas as dúvidas vêm à tona quanto ao grafismo de telas eletrônicas. Como a luz elétrica pode ser código de linguagem? 
E é para esse assombro que se dirige o pensamento de McLuhan quando, já no contexto da concepção dos meios como linguagem, encaminha a premissa do pensamento icônico gerado pela percepção e pela cognição em ambientes eletrônicos. Aqui, a noção de diagrama é fundamental, porque, culturalmente falando, os meios são produtos da tecnologia que explicita uma cadeia de outras relações culturais de signos e linguagens. $\mathrm{O}$ ambiente remonta, pois, a uma ecologia de sistemas e processos de interação e de envolvimento. Há um movimento muito claro da compreensão semiótica quando mostra o diagrama revelado no entendimento, em que o pensamento icônico desvela o próprio modo de pensar.

No quadro de aproximações alcançadas pelo pensamento icônico, os meios foram apreendidos em sua condição de meios frios e quentes. Porque convocam um espectro maior de relações de similaridade; coube aos meios frios a exigência de um maior envolvimento e participação. Ainda no entendimento de McLuhan, icônico serão o pensamento, a interação e o próprio homem num espaço de relações fundamentalmente diagramáticas.

O pensamento icônico de que se ocupou McLuhan resulta da experiência de comunicação com os meios tecnológicos a partir da invenção do alfabeto. Pressupõe, portanto, um encadeamento de relações diagramáticas que, por suas peculiaridades, revelou formações de espaço por meios de dimensões não necessariamente visuais. Quer dizer: o espaço dos meios no ambiente criado pela eletricidade não se define pela visualidade, mas sim pela invisibilidade. Nós não percebermos visualmente o ambiente, mas sim as relações ativas de natureza vibratória. Icônico aqui diz respeito ao caminho explicativo que compõe o diagrama de ressonância, e não de visualidade. Isso, contudo, não quer dizer que o espaço icônico gerado pela ressonância se coloque em oposição ao espaço visual. $\mathrm{Na}$ verdade, o conceito de espaço ressonante - que em vários momentos McLuhan define como espaço acústico - valoriza simultaneidade, integração, envolvimento, participação, integração. Se manifesta oposição, ela fará frente à noção de limite, de lugar, de sucessividade, uma coisa depois da outra.

No contexto do ambiente e da invisibilidade, o espaço pode ser dimensionado enquanto movimento, ressonância ou vibração. Nesse sentido, a definição de espaço orienta-se pela constituição diagramática de padrões. Longe de confinar a representação num único órgão 
3. Dialogamos aqui com a ideia do McLuhan's wake em que seu entendimento, levado por intuições ao modo do Finnegan's wake, de James Joyce, constrói pontos de vista sobre si mesmo e sobre o mundo. sensorial, o processo icônico, observado nos ambientes constituídos pelos meios de comunicação eletrônicos, opera pela intensificação, pela simultaneidade e pela complementaridade das sensações.

Os meios frios, por suas características de incompletude, convidam ao envolvimento e à participação graças ao despertar da percepção para associações de similaridade e para intuições. Em eventos como esses, desperta o "homem icônico"3, aquele que "não preenche o espaço com objetos", mas, pelo contrário, "faz o espaço", quer dizer, opera a montagem de diagramas relacionais de percepções simultâneas. Com isso, parece-lhe que "a forma do ícone tende a não ser tanto um espaço tridimensional quanto um espaço feito, modelado, modulado, ressonante" (McLUHAN, 2005, p. 101). O homem icônico assim concebido não é o homem formado pela leitura, mas o "homem tela" que se envolve com o grafismo eletrônico e, literalmente, é envolvido por ele, formando um espaço ressonante. Tal envolvimento McLuhan observa num meio como a televisão e nos ambientes de espaço ressonante que ela projeta sob forma de luz, de pontos luminosos em feixes de emissão contínua. Manter no horizonte a noção de televisão como meio frio é aqui premissa fundamental do entendimento do pensamento icônico e de seu modo de operar a partir da composição de diagramas.

\section{Informação codificada no ambiente da eletricidade}

Enquanto princípios heurísticos de investigação, as noções de meios frios e quentes merecem ser consideradas como metáforas conceituais pelas quais são representados os graus de envolvimento e participação "com os e nos" meios de comunicação. A dimensão icônica da metáfora sustenta a configuração do caminho explicativo das hipóteses examinadas. É hora de introduzir outra face de nosso argumento: os meios frios e quentes em representação e codificação do processo eletrônico. Do mesmo modo como o alfabeto é o código fundador de toda a cultura visual representada, sobretudo, pela força da escrita (McLUHAN \& McLUHAN, 1988), a luz elétrica foi tomada como o código da cultura dos meios e dos espaços de ressonância acústica (McLUHAN, 1998; 1971). Diferentemente da sequência causal, a simultaneidade sustenta a descontinuidade e o multidirecionamento. No limite, o código discreto do alfabeto 
e, de certo modo, do espaço visual passa a conviver com o código contínuo do ambiente da luz elétrica. Convívio que, tecnicamente, é fruto de processamento de padrões da codificação elétrica em circuitos.

Com base em tal raciocínio, McLuhan especula sobre o estatuto da cultura em que a visualidade, submetida à conquista da eletricidade, conjuga códigos e os exprime em termos sensoriais de audiovisualidade, cinese e tatilidade. Observa que os meios eletrônicos desenvolvidos a partir de tais conjugações, sobretudo a televisão, nascem da mutualidade de envolvimento e participação. Quando envereda pelo entendimento da linguagem da televisão, descobre que os códigos que a constituem passam pela "transdução" elétrica na emissão sonora, da palavra, de projeção de luz, de movimento óptico, que, na saída, constrói uma imagem sonora, em movimento e com projeção tátil no ambiente. A ideia de participação e envolvimento, própria de um meio frio, torna-se um padrão estrutural do próprio fenômeno responsável pela constituição tecnológica do meio, a transdução. Nas noções de homem-tela e de tela-luz, projeta-se o fenômeno da transdução, do qual nos aproximamos neste momento. Ela não é apenas uma grande metáfora conceitual formulada por McLuhan a partir de sua noção de meio frio. Trata-se de uma exploração sobre a complexidade do envolvimento ambiental do meio elétrico em sua capacidade de levar às últimas consequências o processo de informação, graças à descoberta dos padrões de funcionamento dos códigos geradores de linguagens elétricas.

Sabemos que informação pressupõe movimento. O estudo da informação, seja nas disciplinas da vida ou da engenharia, seja na comunicação, seja nas artes, diz respeito à passagem de um estado a outro. A transformação de "estado" define o caráter elementar da informação e a finalidade última do processo de significação, quando informação se torna mensagem. Nesse aspecto, o movimento da informação cumpre a trajetória que vai do desconhecido ao conhecido e, com isso, informação é, sobretudo, também descoberta - ou invenção do código a partir do qual a passagem de um estado ao outro é consubstanciada. É o código que permite à informação transmitir mensagem ou informação codificada, passível de decodificação e também de recodificação.

$\mathrm{Na}$ base do conceito de informação, encontra-se a ideia de quantidade, de matéria e de energia, tal como alcançamos a de- 
finição na físico-química. A quantificação propiciou o desenvolvimento da teoria da informação em máquinas e em processamentos tecnológicos (SHANNON, 1948). Contudo, no contexto da comunicação humana, das artes e da própria vida, humana ou não, é da mudança da quantidade em qualidade que estamos falando. Logo, essa é a mudança que interessa quando estudamos a informação em estados de transformação.

No contexto da circulação social de informação cultural pelos meios tecnológicos de comunicação, os processos e os produtos são, via de regra, focalizados a partir da transmissão das mensagens. Além de consagrar o modelo unidirecional de transmissão, essa concepção considera a existência de um código único encarregado de transmitir mensagens entre fonte e destino. Sabemos que tal entendimento contribuiu para a compreensão de diferentes processos de transmissão de informação em áreas igualmente distintas, tais como a biologia, a engenharia e a linguística, dentre outras. Em todas elas, o processo de transmissão é entendido como deslocamento polarizado da informação por força da ação de um código comum. Tal formulação compreende, contudo, apenas a mecânica da transmissão. Nada afirma sobre a dinâmica transformadora de uma dimensão a outra, quando a experiência se transforma em informação codificada capaz de potencializar o campo da significação, do sentido.

A transformação da experiência em informação codificada diz muito do processo tecnológico de comunicação. Antes mesmo de ser objeto de transmissão, a experiência passa por intervenções de códigos culturais, para só então ser oferecida como informação codificada. Tais intervenções implicam a tradução de um nível de interação com o mundo em outro, que é a condição para a transmissão, não como um ato mecânico, mas como operações cognitivas de transformações da experiência e do próprio ato de observar, de perceber, de conhecer e de dar a conhecer. Pouco do que se consagrou sobre transmissão, codificação-e-decodificação e, portanto, sobre decifração diz respeito à transformação da experiência. Se o eixo de nosso raciocínio se conduz pelo entendimento do pensamento icônico e das hipóteses explicativas, é preciso jogar luz sobre o ato transformador diverso por natureza. Para esse entendimento, contribuem os desdobramentos do envolvimento como transdução de processos nos ambientes de eletricidade.

Deixemos de lado a noção de informação como aquilo que se 
transmite mecanicamente. Recuperemos a notável concepção de Claude Shannon de informação como quantidade 4 e avancemos rumo aos padrões em que a tradução de quantidades em qualidades resulta da transdução. Esse é o lugar da ação dos códigos culturalmente elaborados com mutualidade de relações e diferentes graus de envolvimento e participação ambiental.

O que são os nossos códigos culturais, tais como as letras do alfabeto, os números, as formas geométricas, os dígitos, senão quantidades transformadoras e geradoras de articulações organizadas de sentidos, como palavras, equações, medidas, pinturas, desenhos? A informação assim codificada é também qualificada, isto é, dotada de sentido, como toda experiência. Enquanto tal, se encarrega de fornecer padrões a partir dos quais a informação pode ser traduzida em estruturas e gerar envolvimento e participação em diferentes esferas.

A transformação da experiência em processo informativo exige muito mais do que decodificação e decifração. É preciso interagir com as diferentes formas de transdução que o trabalho dos códigos culturais realiza para lidar com o conhecimento, seja na esfera de produção, seja na de enunciação ou de transmissão. Não da linha automática de transmissão, mas no complexo mundo das relações perceptuais e cognitivas.

Reconhecer a mutualidade de relações implica lidar com dimensões que correm pelo interior e pelo exterior do sistema - vale dizer, com as diferentes esferas de envolvimento e participação. No caso dos meios eletrônicos de comunicação, trata-se de observar não apenas a tradução que McLuhan concebeu como extensão. $\mathrm{Na}$ continuidade desse raciocínio, ocorre a transdução, uma vez que o envolvimento conta com a participação de diferentes constituintes do sistema: a saber, os códigos tecnológicos e os códigos perceptuais e cognitivos por meio dos quais se processa a interação humana.

\section{Transdução no movimento dos códigos nos circuitos elétricos}

Transdução 5 é um termo introduzido na física e na biologia para designar a transformação e a conformidade de fenômenos a partir de propagações, seja em processos gerais de transmissão, seja em deslocamentos de uma dimensão a outra. Nos estudos genéticos, a transdução foi observada na transferência de genes entre bactérias. Já

\begin{abstract}
4. Baseamo-nos em afirmações como a que segue: "The fundamental problem of communication is that of reproducing at one point either exactly or approximately a message selected at another point. Frequently the messages have meaning; that is they refer to or are correlated according to some system with certain physical or conceptual entities. These semantic
\end{abstract} aspects of communication are irrelevant to the engineering problem. The significant aspect is that the actual message is one selected from a set of possible messages. The system must be designed to operate for each possible selection, not just the one which will actually be chosen since this is unknown at the time of design. If the number of messages in the set is finite then this number or any monotonic function of this number can be regarded as a measure of the information produced when one message is chosen from the set, all choices being equally likely" (SHANNON, 1948, p. 1).

5. Nossa introdução ao processo de transdução foi iniciado com base nos conceitos de T. Sebeok (1995), R. Jakobson (1971) e I. Lotman (1978), desenvolvidos no capítulo da tese de livre-docência Língua entre linguagens: a argumentação gráfica na comunicação da ciência (MACHADO, 2011). 
na física, observou-se a transdução em processos de transformação em que uma forma de energia se transforma em outra cuja natureza difere da anterior; por exemplo, quando a voz se transforma em onda na propagação de um circuito elétrico como um alto-falante. Trata-se de um circuito eletrônico - dispositivos (ou sistemas) capaz de "transformar um sinal de entrada de natureza mecânica ou eletromagnética, como som e luz, em sinais elétricos de saída, ou o processo inverso, que transforma sinais elétricos em som, ou luz" (RODITI, 2005, p; 226). Transdução corresponde, assim, a um mecanismo de transferência entre esferas diferenciadas de um domínio de transformação do próprio movimento em sua propagação. Como se trata de ocorrência em movimento, é possível reconhecer um comportamento em que uma esfera acaba funcionando como um princípio de estruturação para outra, alimentando, continuamente, o movimento de propagação.

A noção de princípio estruturante observada na transdução física manifesta-se de igual modo nas atividades dos neurotransmissores quando, nos processos de transmissão de informação, ocorre a transformação da própria interpretação entre fonte e destino. Quer dizer, na transferência não ocorre um acordo, mas sim uma "resposta" distinta da mensagem formulada pela fonte. O processo de transdução, nesse caso, evidencia na resposta a modificação dos processos envolvidos sem, contudo, aniquilar o impulso que o modifica. A resposta implica, pois, uma análise diferenciadora, em que o princípio estruturante torna-se potencialmente gerador das distinções que pontuam aquilo que muda e aquilo que permanece num movimento de transformação.

Tomar a resposta como chave conceitual da transdução implica, no contexto de nosso raciocínio, incluir classes de transformações não restritas aos processos físico-químico e biológico. Em que medida o pensamento pode ser "pensado" na chave da transdução? A hipótese já levantada sobre o pensamento icônico constitui nossa alternativa mais eficiente neste momento.

Além de emergirem como resposta na experiência, os estudos de interação e de comunicação social ajudaram a alcançar um conhecimento dentro da esfera cultural e simbólica, focando o campo da experiência perceptual e cognitiva em processos de mediações tecnológicas. Sob o viés da cultura, a análise da transdução se enriquece, uma vez que o homem se torna um centro de atravessamen- 
to das diferentes esferas da experiência transdutora: química, física, tecnológica, biológica, cultural, psíquica e social. O pensamento icônico pode ser dimensionado a partir dessas diferentes esferas.

Justificada, pelo menos em tese, a constituição da transdução nos ambientes de comunicação mediada, resta-nos situar o ponto de partida: a noção de meio como tradução, uma das hipóteses de McLuhan derivada do movimento que lhe parecia responsável pelo fenômeno da extensão. Se não o conceito, pelo menos o processo da transdução foi tangenciado por McLuhan. Com o objetivo de explicitá-lo com o nosso entendimento, consideramos tal tradução tanto uma formulação generalizada para a interpretação analítica no ambiente quanto um modo de ação do próprio princípio estruturante. Em ambos os casos, estamos orientados pelo e no pensamento icônico.

Vimos que uma das características fundamentais do pensamento icônico é a semiose da representação, no movimento do signo por outros signos que não necessariamente o completem, mas que apresentem respostas mais significativas às suas demandas presentes. A resposta assim concebida reporta-se a ambientes, possibilidades, envolvimento e participação presente - por conseguinte, de simultaneidade e mutualidade de relações.

Seria forçado atribuir a todos os meios e a todas as formas culturais a capacidade de desenvolvimento da resposta e do pensamento icônico, sem o risco de cair em generalização superficial e tautológica desprovida de sentido. Para isso, vem em nosso socorro a polêmica concepção de meios frios. Ganham um estatuto de hipótese explicativa não apenas o pressuposto teórico de McLuhan, mas, sobretudo, seus argumentos em que televisão figura como meio frio privilegiado em suas explorações. No contexto de nossa análise, o meio televisão prima por características tecnológicas que, focalizadas a partir de seus efeitos, desenham um outro quadro do envolvimento e da participação; da resposta e do pensamento icônico; da transdução dos circuitos elétricos em grafismos de luz projetados em tela e no ambiente. E, o que é mais importante, o meio televisão permitiu viver a experiência do espaço acústico ressonante como nenhuma outra formação cultural havia permitido antes.

Comecemos pelo refinamento da afirmação segundo a qual o estudo de McLuhan sobre o meio televisão contribui para a explo- 
ração da visualidade, do grafismo eletrônico da imagem e do envolvimento provocado pela performance oral. Todas essas noções são apenas premissas de partida, ou melhor, os efeitos explícitos a partir dos quais se desenvolveu a exploração mais funda e complexa sobre as implicações perceptuais e cognitivas na cultura.

$\mathrm{Na}$ continuidade do que investigara a respeito da tecnologia do alfabeto e da cultura visual que gravitou em torno dela, McLuhan segue na exploração da tecnologia elétrica e do espaço acústico ressonante - sua hipótese explicativa mais desafiadora. O meio televisão implodiu a cultura visual da base alfabética ao tomá-la como princípio estruturante cuja contribuição para a explosão do processo elétrico é inegável, mas não determinante da natureza dos meios e das linguagens elétricas. Uma aproximação elementar com a natureza elétrica daquilo que vai pela tela da televisão passa pela transdução: o trabalho dos circuitos elétricos em termos de processamento de dados, a sintetização da luz em pontos e linhas, a consequente compressão do espaço-tempo. A projeção que se convencionou chamar de "visual" não lida com uma coisa depois da outra, mas com simultaneidades: tudo acontece ao mesmo tempo, sob fronteiras, excedendo espaços. Reconhecer a natureza elétrica da cultura de tela é incluir nos algoritmos de seu funcionamento a transdução de seus códigos num ambiente que é, sobretudo, espaço acústico ressonante. O princípio estruturante da transdução desafia a compreender a projeção em tela como um excedente ambiental para além da visualidade.

A peculiaridade da televisão como um meio frio pode ser mais propriamente dimensionada se, na reprodução em tela de imagem e som em regime de oralidade, acrescentarmos o excedente sensorial em tempo presente. O raciocínio que encaminha tal proposição afirma:

A peculiaridade da televisão, na medida em que se distingue das fotografias e do cinema, é que a imagem é constituída por luz através; iluminações móveis do mosaico projetam-se no espectador. O modo de comunicação pela luz através, exigindo a iluminação total de dentro para fora, é impressionantemente diferente dos modos analíticos de instrução primária (alfabetização), que criam um hábito de percepção e análise que ignora deliberadamente, e por meios organizados, tudo menos uma coisa de cada vez (CARPENTER \& McLUHAN, 1980, P. 15). 
Os pontos da tríade conceitual ressaltam as premissas: "Luz através"; "dentro para fora"; "simultaneidade" (esta citada pela negação de "uma coisa de cada vez"). A triangulação do pensamento - coerente com a própria noção de mosaico - mostra o esforço de compreender não apenas a natureza da luz, mas a transdução de sua ubiquidade no espaço.

Por um lado, os pontos de luz incidem no sensório como um todo, e não apenas no olho; por outro, a luz projetada em backscreen, isto é, por detrás da tela, transborda para o espaço exterior, que não é só do lugar, mas do corpo-mente. Luz através não é apenas luz que ilumina, mas luz que penetra superfícies em diferentes esferas, de estruturas e padrões de funcionamento, como é o caso do envolvimento e da participação, seja com a complementação do espectador, seja como a significação do percebedor e a interpretação da mente. Ainda que na tela ocorra uma reprodução visual, não é apenas de visualidade que se constitui a organização do espaço-ambiente. Quer dizer, no movimento da luz que atravessa e, por conseguinte, difunde-se, o que é dentro e o que é fora quando o próprio movimento da luz não para, mas é contínuo e simultâneo?

Se entendemos o processo de transdução que a videografia realiza na tela (do ambiente, do corpo, da mente), de modo a compor o espaço acústico, encontramos não necessariamente uma resposta, mas uma hipótese explicativa que estava apenas sendo anunciada (bem ao gosto das explorações de McLuhan). Experimentos artísticos desenvolvidos com luz, com sombras, com telas em circuitos elétricos, com espaço sensorial em atravessamentos de simultaneidade são conquistas do período que marcam o centenário do pensamento que ensaiou algumas dessas possibilidades.

Na linha que nos aproxima da transdução, há que se atentar para a projeção como excedente, não de visão num campo visual (como nos ensinou Mikhail M. Bakhtin, 1989, p. 28 e segs.), mas de signos em contato e sob fronteiras, que distingue sem isolar aquilo que está dentro daquilo que vai para fora. Não a tela, mas o espaço de contato torna-se o grande assombro, aparentemente mosaico de luz, movimento e som. E McLuhan se pergunta: "Por que a televisão, que parece tão visual, é um veículo tátil? Por que a televisão, que parece tão superficial, é um veículo profundo? E por que a televisão, que parece ter uma orientação tão agudamente literal, é um veículo mítico?” (McLUHAN, 2005, p. 89). 
Cogitar uma dimensão tátil num espaço que pode ser até mesmo mítico não é para qualquer entendimento dos processos de percepção e de interação. O questionamento de McLuhan busca alcançar as intersecções que não abandonam nem mesmo aquilo que vai pelo imaginário, o que exprime em suas instigantes explorações do espaço mítico, quase cósmico, do ambiente multissensorial de tão diversificados cruzamentos.

Ainda que a tatilidade se reporte ao ambiente de projeção sensorial, o raciocínio resvala para a esfera da percepção de estruturas e padrões do signo icônico, observada no funcionamento da própria tecnologia. Mesmo sem ter chegado à era digital, McLuhan entendeu que a câmera de tevê processa dados, cria e manipula padrões, captura ambientes e os "modeliza" icônica e diagramaticamente, e não por instantâneos fotográficos, como era o padrão dos obturadores fotográficos de seu tempo (McLUHAN, 2005, p. 101). Esse funcionamento também diz respeito ao envolvimento e à participação de meios frios. Afinal, "o modo tátil de perceber é imediato, mas não é especializado” (McLUHAN, 1971, p. 376), o que implica transdução e um modo operativo muito mais intuitivo.

Quando o pensamento icônico abre-se para a intuição, uma das consequências é o favorecimento de possibilidades combinatórias, caminho natural da abdução. No estudo sobre os juízos perceptivos, Peirce define a abdução como o exercício livre do pensamento, aquele sem o qual nenhuma criação ou descoberta acontece. Nos estudos dos meios, seguindo as explorações de McLuhan, observa-se que a percepção do espaço ressonante de fronteiras e contatos encaminha as abduções que emergem quando o que está em jogo são padrões, e não estruturas já elaboradas. Quer dizer, não se trata de considerar apenas a audiovisualidade ou o movimento da projeção tátil da "luz através". Na esfera perceptual e cognitiva, trata-se de perceber o diagrama relacional de figura e fundo (figure and ground).

Em livro póstumo, editado por Eric McLuhan (McLUHAN \& McLUHAN, 1988), apresenta-se uma síntese conceitual que, como toda concepção abdutiva, elabora hipóteses explicativas sobre explorações que merecem investigações aprofundadas. Assim entendemos o caminho que nos levou ao entendimento do pensamento icônico que formula o diagrama da figura/fundo. Quer dizer, para além daquilo que se revela num campo visual, há uma fina linha de cruzamento em que se projetam simultâneas figuras que não 
se opõem ao seu fundo, mas o complexificam. É disso que se trata quando a tela projeta pontos de luz atravessados na superfície e lançados para o espaço de ambientes.

Até que ponto a transdução dos códigos elétricos em sistema de projeção de luz gera processos interativos de comunicação foi parte das investigações desenvolvidas por McLuhan e retomadas, num outro contexto, por Paul Virilio em suas reflexões sobre as "janelas catódicas" (VIRILIO, 1993, p. 13), aquelas representadas pelas interfaces de telas cuja profundidade de campo flutua num "éter eletrônico desprovido de dimensões espaciais, mas inscrito na temporalidade única de uma difusão instantânea" (VIRILIO, 1993, p. 9-10). O aprimoramento do sistema tecnológico seguiu em frente, e outros caminhos explicativos estão em marcha, muitos deles sem olhar para trás, para a luz que os ilumina.

\section{Considerações finais}

Se o envolvimento projetou a dimensão tátil, a simultaneidade de eventos possíveis graças à projeção da "luz através" da tela-circuito e espaço-ambiente lhe acrescentou a configuração de um espaço ambiental. Com ele, divisou a constituição do espaço acústico, um de seus conceitos mais perturbadores. Primeiro porque a condição acústica não se refere diretamente ao som; segundo porque o espaço acústico não se coloca como o contracampo do espaço visual. O espaço acústico cria um ambiente de relações em que simultaneidade, ubiquidade, invisibilidade e participação tornam-se favoráveis à intuição, sem a prevalência de um único modo de percepção. $\mathrm{O}$ espaço deixa de ser lugar de continência para as coisas e torna-se ambiente. A tela, com seus pontos de luz, delineou esse espaço de fronteiras e a partir dele permite adentrar no vasto âmbito da compreensão que McLuhan formulou para espaço e meio ambiente. Vale lembrar, ainda, que os meios de tela tornam-se grandes espaços de experimentação graças às confluências que oferecem, não pelo seu caráter intrínseco de superfície. Tela aqui é um espaço de mediação e, portanto, de fronteira não limitada à superfície.

O que está em jogo, na verdade, é a percepção de um novo espaço: o espaço ambiental ressonante, isto é, espaço apreendido pela conjugação de diferentes sentidos, o sensus communis - o sentido 
de todos os sentidos. Não se trata de intelecto; tampouco pode ser restringido à sensação. Define-se, sobretudo, pelo envolvimento, pela invisibilidade e pela simultaneidade. Aproxima-se do espaço acústico intervalar em que as regiões de contato são autoalimentadas por novas relações espaciais de um estado de cultura pós-visual. Porque resulta de uma participação ativa de todos os sentidos, a emergência do sensus communis está condicionada ao treino de percepção; portanto, é questão de educação ou de descoberta. Pode ser adquirido, assim como se adquire um hábito.

No pensamento semiótico, o hábito corresponde, sim, a uma lei do pensamento. Enquanto tal, excita reações que não eliminam formulação de hipóteses e treinos de percepção para as experiências do mundo, como essas que desenvolvemos neste ensaio. 


\section{Referências}

BAJTÍN, M. M. Estética de la creación verbal.

México D.F.: Siglo XXI, 1989.

CARPENTER, E.; McLUHAN, M. "Espaço acústico”. In:

Revolução na comunicação. Rio de Janeiro: Zahar, 1980.

CAVELL, R. McLuhan in space: a cultural geography.

Toronto: Toronto University Press, 2002.

DELEUZE, G. “The diagram”. In: The Deleuze Reader.

New York: Columbia University Press, 1993.

JAKOBSON, R. Lingüística e comunicação. São Paulo:

Cultrix, 1971.

LOGAN, R. K. Understanding new media: extending Marshall

McLuhan. New York: Peter Lang, 2010.

LOTMAN, I. A estrutura do texto artístico. Lisboa: Estampa, 1978. La semiosfera: semiótica de la cultura y del texto.

Madrid: Cátedra, 1996.

MACHADO, I. Lingua entre linguagens: a argumentação gráfica na comunicação da ciência. Tese (livre-docência).

São Paulo: Escola de Comunicações e Artes, Universidade de São Paulo, 2011.

McLUHAN, M. A galáxia de Gutenberg: a formação do homem tipográfico. São Paulo: Cia. Editora Nacional, 1977. McLuhan por McLuhan: conferências e entrevistas.

Rio de Janeiro: Ediouro, 2005.

Os meios de comunicação como extensões do homem.

São Paulo: Cultrix, 1971.

Understanding media: the extensions of man. Cambridge e London: The MIT Press, 1998.

McLUHAN, M.; FIORE, Q. The medium is the massage: an inventory of effects. New York: Bantam Books, 1967. Os meios são as massagens. Rio de Janeiro: Record, 1969 .

McLUHAN, M.; McLUHAN, E. Laws of media: the new science. Toronto: University of Toronto Press, 1988.

McLUHAN, M.; PARKER, H. O espaço na poesia e na pintura através do ponto de fuga. São Paulo: Hemus, 1975.

McLUHAN, M.; POWERS, B. R. "Exploraciones en el espacio visual y el acústico”. In: La aldea global. Barcelona: Gedisa, 1996. 
McLUHAN, M.; WATSON, W. Do clichê ao arquétipo.

Rio de Janeiro: Record, 1973.

PEIRCE, C. S. Collected papers. Cambridge: Harvard University Press, 1933. . "Conferências sobre o pragmatismo". In: Escritos coligidos. São Paulo: Abril, 1980 (Os Pensadores).

PEREIRA, V. A. Estendendo McLuhan: da aldeia à teia global. Porto Alegre: Sulina, 2011.

RODITI, I. “Transdução”. In: Dicionário Houaiss de física.

Rio de Janeiro: Objetiva, 2005.

SEBEOK, T. “Comunicação”. In: NEIVA, E.; RECTOR, M. (Org.). Comunicação na era pós-moderna. Petrópolis: Vozes, 1995.

SHANNON, C. E. "A mathematical theory of communication". Reimpresso com correções de The Bell System Technical Journal, vol. 27, p. 379-423, 623-656, jul.-out. 1948. Disponível em: <http://en.wikipedia.org/wiki/A_ Mathematical_Theory_of_Communication>. Acesso em: 25 jan. 2012.

VIRILIO, P. O espaço crítico e as perspectivas do tempo real. Rio de Janeiro: 34 Letras, 1993.

WIENER, N. Cibernética e sociedade: o uso humano de seres humanos. São Paulo: Cultrix, 1968. 